\title{
PENGARUH BIAYA PRODUKSI TERHADAP PENETAPAN HARGA JUAL KOPI BUBUK PADA UD. USAHA JADI DI DESA GAMPONG JAWA KECAMATAN IDI RAYEUK
}

\author{
Hanisah $^{1}$, Cut Gustiana ${ }^{2}$ dan Saiful Nizar ${ }^{2}$ \\ ${ }^{1}$ Dosen Fakultas Pertanian Universitas Samudra \\ ${ }^{2}$ Dosen Fakultas Pertanian Universitas Samudra \\ ${ }^{2}$ Mahasiswa Program Studi Agribisnis Fakultas Pertanian Universitas Samudra
}

\begin{abstract}
ABSTRAK
Tujuan penelitian ini adalah untuk mengetahui dan menganalisis pengaruh biaya bahan baku, biaya tenaga kerja dan biaya overhead terhadap penetapan harga jual kopi bubuk pada UD. Usaha Jadi di Desa Gampong Jawa Kecamatan Idi Rayeuk Kabupaten Aceh Timur. Penelitian ini menggunakan metode studi kasus. Lokasi penelitian ditetapkan di Kecamatan Idi Rayeuk Kabupaten Aceh Timur dengan pertimbangan bahwa kecamatan tersebut merupakan daerah yang ada usaha pengolahan kopi bubuk. Objek pada penelitian ini hanya dibatasi pada pengusaha pengolahan kopi bubuk pada UD. Usaha Jadi di Desa Gampong Jawa Kecamatan Idi Rayeuk Kabupaten Aceh Timur. Ruang lingkup penelitian ini hanya dibatasi pada pengaruh biaya bahan baku, biaya tenaga kerja dan biaya overhead terhadap penetapan harga jual kopi bubuk pada UD. Usaha Jadi di Kecamatan Idi Rayeuk. Waktu penelitian dilaksanakan pada Bulan Maret-April 2017.

Hasil penelitian diperoleh Persamaan Regresi Linear Berganda sebagai berikut: $\hat{\mathrm{Y}}=-49,28-4,38 \mathrm{X}_{1}+16,64 \mathrm{X}_{2}+0,78 \mathrm{X}_{3}$. Hasil perhitungan koefisien determinasi menunjukkan bahwa besarnya $\mathrm{R}^{2}=0,8643$. Ini berarti variasi terhadap naik turunnya penetapan harga jual kopi bubuk (Y) dipengaruhi oleh biaya bahan baku $\left(\mathrm{X}_{1}\right)$, biaya tenaga kerja $\left(\mathrm{X}_{2}\right)$ dan biaya overhead $\left(\mathrm{X}_{3}\right)$ sebesar 86,43\% dan sisanya sebesar 13,57 \% lagi dipengaruhi oleh faktor lain yang tidak ikut diteliti dalam penelitian ini. Hasil pengujian secara serempak biaya bahan baku $\left(\mathrm{X}_{1}\right)$, biaya tenaga kerja $\left(\mathrm{X}_{2}\right)$ dan biaya overhead $\left(\mathrm{X}_{3}\right)$ secara serempak berpengaruh sangat nyata terhadap penetapan harga jual kopi bubuk (Y). Hasil pengujian secara parsial untuk biaya bahan baku tidak berpengaruh secara nyata terhadap penetapan harga jual kopi bubuk. Hasil pengujian secara parsial untuk biaya tenaga kerja berpengaruh sangat nyata terhadap penetapan harga jual kopi bubuk. Hasil pengujian secara parsial untuk biaya overhead tidak berpengaruh terhadap penetapan harga jual kopi bubuk.
\end{abstract}

Kata Kunci: Kopi, bahan baku, tenaga kerja, biaya over head

\section{PENDAHULUAN}

Perkembangan industri pengolahan bubuk kopi diharapkan mampu meningkatkan peranannya dalam penyediaan kebutuhan pasar dalam negeri. Untuk memenuhi permintaan konsumen dengan mutu yang baik dan harga bersaing, masing-masing perusahaan bubuk kopi berusaha untuk memenuhi permintaan pasar tersebut hingga dapat meningkatkan penjualan dengan tujuan memperoleh keuntungan sesuai dengan kemampuan dan kapasitas sumberdaya yang ada.

Aceh merupakan salah satu daerah penghasil kopi di Indonesia, yang barasal dari Aceh Tengah dan Aceh Tenggara. Kopi Aceh merupakan salah satu kopi yang berbahan dasar arabika dan robusta yang sangat terkenal dan 
termasuk kopi berkualitas di Asia. Jenis kopi yang dibudidayakan di Provinsi Aceh sebagian besar merupakan jenis arabika dan sebagiannya lagi jenis robusta.

Dengan adanya hasil pertanian dari komoditi kopi di Aceh maka lahirlah industri-industri pengolahan biji kopi menjadi bubuk kopi. Seperti yang kita ketahui sekarang ini di Aceh banyak terdapat usaha-usaha penggilingan kopi, dari industri kecil hingga industri besar. Industri-ndustri ini mampu memenuhi kebutuhan permintaan kopi di daerah dan sekarang sudah mampu memasarkan produknya hingga ke luar daerah Aceh seperti Sumatra Utara.

Kecamatan Idi Rayeuk merupakan salah satu kecamatan yang mempunyai industri pengolahan kopi bubuk, industri tersebut merupakan pemasok kopi bubuk di Kecamatan Idi Rayeuk dan sekitarnya untuk memenuhi permintaan terhadap kopi bubuk di daerah tersebut. Konsumen utama produk kopi bubuk adalah seluruh kalangan masyarakat, baik kalangan masyarakat menengah ke atas maupun menengah ke bawah.

Dalam menjalankan usahanya perusahaan tersebut tidak terlepas dari penggunaan faktor produksi yang meliputi sumber daya alam, berupa bahan baku yang digunakan, tenaga kerja, modal dan kelengkapan lainnya, dimana semua faktor produksi tersebut satu sama lain saling berkaitan. Perusahaan yang mengolah bahan baku menjadi barang jadi yang akan dijual kepada konsumen, menandakan bahwa perusahaan tersebut sedang melakukan kegiatan produksi. Dalam kegiatan produksi, suatu perusahaan tidak boleh melupakan komponen biaya produksi. Pengendalian biaya produksi merupakan salah satu kunci keberhasilan dari pengendalian produksi secara keseluruhan. Tenaga kerja merupakan segala kegiatan manusia baik jasmani maupun rohani yang ditujukan untuk kegiatan produksi. Faktor tenaga kerja memegang peranan penting dalam berbagai macam dan jenis serta tingkatan kegiatan produksi. Dalam kegiatan produksi tidak lepas dari tenaga kerja karena yang sangat dominan untuk melancarkan kegiatan produksi hingga memperoleh hasil produksi dari suatu kegiatan produksi adalah tenaga kerja. Selain bahan baku dan tenaga kerja, komponen produksi kopi bubuk yang lain adalah biaya overhead. Biaya overhead terdiri dari biaya penyusutan, sewa tempat, bahan bakar mesin, pemeliharaan mesin dan bangunan, pengemas, listrik, oli dan gemuk. Permasalahannya adalah biaya overhead mengalami kenaikan harga yang cukup signifikan, sedangkan harga jual kopi bubuk di pasar relatif tidak berubah atau sulit dinaikkan.

Berdasarkan uraian di atas penulis tertarik meneliti secara mendalam tentang industri pengolahan kopi bubuk yang ada di Kecamatan Idi Rayeuk yaitu di Desa Gampong Jawa. Hal yang akan diteliti adalah bagaimana sektor industri kecil seperti industri pengolahan kopi bubuk dapat berkembang dengan mengkaji pengaruh biaya bahan baku, biaya tenaga kerja, dan biaya overhead terhadap penetapan harga jual kopi bubuk.

\section{Identifikasi Masalah}

Apakah biaya bahan baku, biaya tenaga kerja dan biaya overhead mempengaruhi harga jual kopi bubuk pada UD. Usaha Jadi di Desa Gampong Jawa Kecamatan Idi Rayeuk Kabupaten Aceh Timur

\section{Tujuan Penelitian}

Untuk mengetahui dan menganalisis pengaruh biaya bahan baku, biaya tenaga kerja dan biaya overhead 
terhadap penetapan harga jual kopi bubuk pada UD. Usaha Jadi di Desa Gampong Jawa Kecamatan Idi Rayeuk Kabupaten Aceh Timur.

\section{Hipotesis}

Biaya bahan baku, biaya tenaga kerja dan biaya overhead berpengaruh terhadap penetapan harga jual kopi bubuk pada UD. Usaha Jadi di Desa Gampong Jawa Kecamatan Idi Rayeuk Kabupaten Aceh Timur.

\section{METODE PENELITIAN}

Metode, Lokasi, Objek, Ruang

Lingkup dan Waktu Penelitian

Penelitian ini menggunakan metode studi kasus. Lokasi penelitian ditetapkan di Kecamatan Idi Rayeuk Kabupaten Aceh Timur dengan pertimbangan bahwa kecamatan tersebut merupakan daerah yang ada usaha pengolahan kopi bubuk. Objek pada penelitian ini hanya dibatasi pada pengusaha pengolahan kopi bubuk UD. Usaha Jadi di Desa Gampong Jawa Kecamatan Idi Rayeuk Kabupaten Aceh Timur. Ruang lingkup penelitian ini hanya dibatasi pada pengaruh biaya bahan baku, biaya tenaga kerja dan biaya overhead terhadap penetapan harga jual kopi bubuk pada UD. Usaha Jadi di Kecamatan Idi Rayeuk. Waktu penelitian dilaksanakan pada Bulan Maret-April 2017.

\section{Variabel dan Data yang Diteliti}

Biaya bahan baku (Rp/Bln)

Biaya tenaga kerja $(\mathrm{Rp} / \mathrm{Bln})$

Biaya overhead (Rp/Bln)

Harga Jual $(\mathrm{Rp} / \mathrm{Kg})$

\section{Metode Analisis Data}

Data yang dikumpulkan diolah dan ditabulasikan menurut kebutuhan analisis. Model yang digunakan dalam penelitian ini adalah dengan menggunakan Regresi Linear Berganda. Model tersebut dapat ditulis sebagai berikut :

$$
\mathrm{Y}=\mathrm{a}_{0}+\mathrm{a}_{1} \mathrm{X}_{1}+\mathrm{a}_{2} \mathrm{X}_{2}+\mathrm{a}_{3} \mathrm{X}_{3}+\mathrm{e}
$$
(Sudjana,

$$
\begin{aligned}
& 2005: 332) \text { Keterangan: } \\
& \mathrm{Y} \quad=\text { Harga Jual }(\mathrm{Rp} / \mathrm{Kg}) \\
& \mathrm{X}_{1} \quad=\text { Biaya Bahan Baku } \\
& (\mathrm{Rp} / \text { Bulan) }
\end{aligned}
$$$$
\mathrm{X}_{2} \quad=\text { Biaya Tenaga Kerja }
$$$$
\text { (Rp/Bulan) }
$$$$
\mathrm{X}_{3} \quad=\text { Biaya Overhead (Rp/Bulan) }
$$$$
\mathrm{a}_{0}, \mathrm{a}_{1}, \mathrm{a}_{2} \text { dan } \mathrm{a}_{3}=\text { Parameter yang }
$$

dicari (koefisien masing-masing variabel bebas)

Selanjutnya dihitung koefisien determinasi $\left(R^{2}\right)$ untuk mengetahui besarnya pengaruh secara keseluruhan. Untuk menguji pengaruh secara serempak variabel Independen $\left(X_{1}, X_{2}\right.$ dan $X_{3}$ ) terhadap variabel dependen (Y). Untuk mengetahui pengaruh variabel bebas terhadap variabel dependen secara parsial digunakan uji " $t$ ".

\section{HASIL PENELITIAN DAN \\ PEMBAHASAN \\ Profil Usaha UD. Usaha Jadi}

UD. Usaha Jadi di Kecamatan Idi Rayeuk Kabupaten Aceh Timur merupakan sebuah usaha yang melakukan kegiatan pengolahan mengolah biji kopi menjadi kopi bubuk. Usaha ini didirikan pada tahun 1990 oleh Almarhum Bapak Abdul Karim dan sekarang dikelola oleh anaknya yang bernama Muhammad Iqbal. Industri ini termasuk kedalam industri kecil karena hanya memiliki tenaga kerja yang berjumlah 5 orang. Tenaga kerja tersebut berasal dari dalam dan luar keluarga. Pendidikan tenaga kerja keluarga umumnya adalah SMP dan SMA. Tenaga kerja di luar keluarga yaitu penduduk setempat dengan tingkat pendidikan umumnya juga SMP dan SMA. Upah tenaga kerja langsung dibayar oleh pengolah dengan jangka waktu per hari dan ada juga yang 
memberikan upah perbulan. Profil pengusaha dalam penelitian ini meliputi umur, pendidikan, pengalaman dalam berusaha sebagai pengusaha kopi bubuk dan besarnya tanggungan keluarga. Karakteristik akan mempengaruhi tingkat keterampilan pengusaha dalam mengelola usaha kopi bubuk, misalnya semakin tinggi tingkat pendidikan yang diperoleh pengusaha maka semakin terampil dalam mengelola usahanya sehingga berpengaruh terhadap kualitas dan pendapatan usaha kopi bubuk yang diperoleh.

\section{Biaya Bahan Baku}

Biaya bahan baku dalam penelitian ini adalah biaya pembelian biji kopi dan biji jagung yang digunakan perusahaan untuk memproduksi kopi bubuk dengan jumlah produksi yang telah direncanakan dan dinyatakan dalam satuan rupiah per bulan. Untuk lebih jelasnya tentang ratarata biaya bahan baku usaha pengolahan kopi bubuk pada UD. Usaha Jadi di Desa Gampong Jawa Kecamatan Idi Rayeuk dapat dilihat pada tabel V-1 berikut ini.

Tabel V-1. Rata-rata Biaya Bahan Baku Pada UD. Usaha Jadi di Desa Gampong Jawa Kecamatan Idi Rayeuk, 2017

\begin{tabular}{|c|c|c|c|c|}
\hline \multirow[b]{2}{*}{ No } & \multirow[b]{2}{*}{ Tahun } & \multicolumn{2}{|c|}{ Biaya Bahan Baku } & \multirow[b]{2}{*}{ Jumlah (Rp/Bln) } \\
\hline & & $\begin{array}{l}\text { Biji Kopi } \\
\text { (Rp/Bln) }\end{array}$ & $\begin{array}{c}\text { Biji Jagung } \\
\text { (Rp/Bln) }\end{array}$ & \\
\hline 1 & 2014 & 6.787 .111 & 2.714 .844 & 9.501 .956 \\
\hline 2 & 2015 & 6.777 .667 & 2.711 .067 & 9.488 .733 \\
\hline 3 & 2016 & 6.847 .000 & 2.738 .800 & 9.585 .800 \\
\hline \multicolumn{2}{|c|}{ Jumlah rata-rata } & 20.411 .778 & 8.164 .711 & 28.576 .489 \\
\hline \multicolumn{2}{|c|}{ Rata-rata/Bln } & 6.803 .926 & 2.721 .570 & 9.525 .496 \\
\hline
\end{tabular}

Sumber : Data primer diolah (2017)

Berdasarkan tabel V-1 diatas dapat dilihat bahwa kebutuhan bahan baku pada usaha pengolahan kopi bubuk pada UD. Usaha Jadi di Desa Gampong Jawa Kecamatan Idi Rayeuk terus meningkat setiap tahunnya. Rata-rata biaya untuk pembelian biji kopi adalah sebesar Rp 6.803.926,-/Bln, rata-rata biaya untuk pembelian biji jagung adalah sebesar Rp 2.721.570,-/Bln dan rata-rata jumlah biaya total untuk biaya bahan baku adalah sebesar Rp 9.525.496,-/Bln.

Biji kopi yang digunakan sebagai bahan baku untuk pembuatan kopi bubuk diperoleh dari para agen yang datang langsung ketempat pengusaha. Rata- rata para agen tersebut sudah berlangganan dengan pengusaha kopi bubuk, sehingga dalam jangka waktu beberapa minggu sekali para agen akan membawa langsung biji kopi yang berasal dari Aceh Tengah, Takengon,
Bener Meriah dan Lampung langsung ketempat pengusaha kopi bubuk. Sedangkan biji jagung diperoleh dari pasar sekitar, karena biji jagung mudah dijumpai dimana saja.

\section{Biaya Tenaga Kerja}

Biaya tenaga kerja merupakan salah satu faktor yang sangat penting dalam kegiatan operasional usaha pengolahan kopi bubuk. Penggunaan tenaga kerja yang efisien dan efektif dapat mempengaruhi terhadap pengeluaran biaya produksi dalam menjalankan usaha pengolahan kopi bubuk. Kegiatan yang dilakukan oleh tenaga kerja pada usaha pengolahan kopi bubuk meliputi jenis kegiatan pengangkutan, penjemuran, pemanggangan, penggilingan, pengemasan dan pemasaran. 
Biaya tenaga kerja terdiri dari biaya tenaga kerja dalam keluarga dan biaya tenaga kerja luar keluarga. Tenaga kerja luar keluarga biasanya merupakan tetangga atau saudara dari pengusaha kopi bubuk yang diketahui telah berpengalaman dalam proses produksi kopi bubuk. Upah tenaga kerja dalam keluarga ditetapkan berdasarkan upah tenaga kerja luar keluarga. Upah yang diberikan berupa upah harian dan ada juga yang dibayar perbulan.

Dalam menghitung besarnya pencurahan tenaga kerja yang diserap

Tabel V-2. Jumlah Penggunaan Tenaga Kerja Pada UD. Usaha Jadi di Desa Gampong Jawa Kecamatan Idi Rayeuk, 2017

\begin{tabular}{|r|l|r|r|r|}
\hline \multirow{2}{*}{ No } & \multirow{2}{*}{ Jenis Kegiatan } & \multicolumn{2}{|c|}{$\begin{array}{c}\text { Penggunaan Tenaga Kerja } \\
\text { TKP/Bln) }\end{array}$} & \multirow{2}{*}{$\begin{array}{c}\text { Total } \\
\text { (HKP) }\end{array}$} \\
\cline { 3 - 4 } & & DK (HKP) & LK (HKP) & \\
\hline 1 & Pengangkutan & 0,00 & 27,89 & 27,89 \\
2 & Penjemuran & 0,00 & 22,02 & 22,02 \\
3 & Pemanggangan & 0,00 & 17,60 & 17,60 \\
4 & Penggilingan & 0,00 & 32,30 & 32,30 \\
5 & Pengemasan & 0,00 & 18,21 & 18,21 \\
6 & Penjualan & 24,67 & 12,05 & 36,71 \\
\hline \multicolumn{2}{r|r}{ Rata-rata } & 24,67 & 130,08 & 154,75 \\
\hline
\end{tabular}

Sumber : Data primer diolah (2017)

Berdasarkan tabel V-2 diatas dapat dilihat bahwa rata-rata jumlah penggunaan tenaga kerja pada industry pengolahan biji kopi UD. Usaha Jadi di Desa Gampong Jawa Kecamatan Idi Rayeuk dari dalam keluarga adalah sebesar 24,67 HKP dan rata-rata jumlah penggunaan tenaga kerja dari luar keluarga adalah sebesar 21,68 HKP.

Tenaga kerja yang digunakan dalam proses pengolahan bubuk kopi banyak berasal dari luar keluarga karena jumlah tenaga kerja dari dalam keluarga sedikit, oleh karena itu disini pengusaha memperkerjakan orang lain untuk mengerjakan pekerjaan yang membutuhkan tenaga-tenaga kerja yang untuk setiap fase kegiatan, selanjutnya dikonversikan kedalam hari kerja pria (HKP) dengan berdasarkan upah yang diberikan pada saat penelitian, dimana satu HKP diartikan seorang tenaga kerja yang bekerja enam jam rata-rata atau dengan upah yang dibayarkan sebesar Rp. 50.000,- per hari kerja. Untuk lebih jelasnya mengenai rata-rata biaya tenaga kerja pada usaha pengolahan biji kopi bubuk pada UD. Usaha Jadi di Desa Gampong Jawa Kecamatan Idi Rayeuk dapat dilihat pada tabel V-2 berikut. berpengalaman dibidang pengolahan biji kopi.

\section{Biaya Overhead}

Biaya overhead dalam penelitian dari biaya penyusutan, sewa tempat, pembelian solar, pemeliharaan mesin dan bangunan, pembelian kayu bakar, pembelian kemasan, listrik, pembelian oli dan gemuk yang dikeluarkan oleh UD. Usaha Jadi dalam rangka proses produksi yang dinyatakan dalam satuan rupiah perbulan. Untuk lebih jelasnya mengenai rata-rata biaya overhead pada usaha pengolahan biji kopi di Kecamatan Idi Rayeuk dapat dilihat pada tabel V-3 berikut ini. ini adalah biaya-biaya pabrik yang terdiri

Tabel V-3. Jumlah Biaya Overhead Pada UD. Usaha Jadi di Desa Gampong Jawa Kecamatan Idi Rayeuk, 2017 


\begin{tabular}{|r|l|r|}
\hline No & \multicolumn{1}{|c|}{ Jenis Biaya } & $\begin{array}{r}\text { Biaya Overhead } \\
\text { (Rp/Bln) }\end{array}$ \\
\hline 1 & Penyusutan Peralatan & 605.377 \\
2 & Sewa Tempat & 443.333 \\
3 & Solar & 1.391 .216 \\
4 & Pemeliharaan Mesin dan Bangunan & 546.253 \\
5 & Kayu Bakar & 637.797 \\
6 & Kemasan & 612.285 \\
7 & Oli dan Gemuk & 224.831 \\
8 & Listrik & 306.278 \\
\hline \multicolumn{2}{r}{ Jumlah } \\
\hline
\end{tabular}

Sumber : Data primer diolah (2017)

Berdasarkan tabel V-3 diatas dapat dilihat bahwa jumlah rata-rata biaya overhead yang dikeluarkan pada UD. Usaha Jadi di Desa Gampong Jawa Kecamatan Idi Rayeuk adalah sebesar Rp 4.767.371,-/Bln, dengan jumlah biaya terbesar terdapat pada biaya pembelian solar yaitu sebesar Rp 4.767.371,-/Bln dan biaya terkecil terdapat pada biaya pembelian oli dan gemuk yaitu sebesar Rp.224.831,-/Bln.

\section{Harga Kopi Bubuk}

Harga kopi bubuk yang dimaksud dalam penelitian ini adalah suatu tingkat harga yang digunakan untuk menjual kopi bubuk yang berlaku pada UD. Usaha Jadi di Desa Gampong Jawa Kecamatan Idi Rayeuk yang dinyatakan dalam satuan rupiah per kilogram. Untuk lebih jelasnya mengenai rata-rata harga kopi bubuk yang berlaku pada UD. Usaha Jadi dapat dilihat pada tabel V-4 berikut ini.

Tabel V-4. Jumlah Harga Kopi Bubuk Pada UD. Usaha Jadi di Desa Gampong Jawa Kecamatan Idi Rayeuk, 2017

\begin{tabular}{|c|c|c|}
\hline $\mathrm{N}$ & Tahun & $\begin{array}{c}\text { Harga } \\
(\mathrm{Rp} / \mathrm{Kg})\end{array}$ \\
\hline 1 & 2014 & 36.250 \\
\hline 2 & 2015 & 42.917 \\
\hline 3 & 2016 & 45.000 \\
\hline & Rata-rata/Bln & 41.389 \\
\hline
\end{tabular}

Sumber : Data primer diolah (2017)

Berdasarkan tabel V-4 diatas dapat dilihat bahwa rata-rata harga kopi bubuk yang berlaku pada UD. Usaha Jadi di Desa Gampong Jawa Kecamatan Idi Rayeuk adalah sebesar Rp 41.389,-/Kg, dengan rata-rata harga tertinggi terdapat pada Tahun 2016 yaitu rata-rata sebesar $\mathrm{Rp} 45.000,-/ \mathrm{Kg}$ dan rata-rata harga terendah terdapat pada Tahun 2014 yaitu sebesar Rp 36.250,-/Kg.

\section{Pengaruh Biaya Produksi Terhadap Harga Jual Kopi Bubuk}

Pengaruh biaya produksi terhadap harga jual kopi bubuk pada UD. Usaha Jadi ditujukan untuk melihat sejauh mana biaya produksi dapat mempengaruhi harga jual kopi bubuk. Hasil analisis diperoleh Persamaan Regresi Linear Berganda sebagai berikut: $\hat{Y}=-49,28$ $4,38 \mathrm{X}_{1}+16,64 \mathrm{X}_{2}+0,78 \mathrm{X}_{3}$ 
Berdasarkan persamaan Regresi Linear Berganda tersebut dapat disimpulkan bahwa :

1. Apabila biaya tenaga kerja dan biaya overhead dianggap tetap, maka setiap penambahan biaya bahan baku sebesar Rp 1.000.000,- maka akan menurunkan penetapan harga jual sebesar Rp 4.380,--

2. Apabila biaya bahan baku dan biaya overhead dianggap tetap, maka setiap penambahan biaya tenaga kerja sebesar Rp 1.000.000,- maka akan menyebabkan penetapan harga jual bertambah sebesar Rp 16.640,-.

Hasil analisis pengaruh serempak (Uji F) diperoleh kesimpulan sebagai berikut Tabel V-5. Uji Secara Serempak (Uji F)

\begin{tabular}{|c|c|c|c|c|c|}
\hline \multirow{2}{*}{ Variabel } & \multirow{2}{*}{ Fcari } & \multicolumn{2}{|c|}{ Ftabel } & \multicolumn{2}{c|}{ Kesimpulan } \\
\cline { 3 - 6 } & & $\alpha=0,05$ & $\alpha=0,01$ & $\alpha=0,05$ & $\alpha=0,01$ \\
\hline $\begin{array}{l}\text { - Biaya Bahan Baku (X1) } \\
\text { - Biaya Tenaga Kerja (X2) } \\
\text { - Biaya Overhead (X3) }\end{array}$ & 67,96 & 2,4 & 3,52 & Fcari $>$ Ftabel & Fcari $>$ Ftabel \\
\hline
\end{tabular}

Sumber : Data primer diolah (2017)

Berdasarkan tabel V-5 di atas, hasil pengujian secara serempak dapat dilihat bahwa $\mathrm{F}_{\text {cari }}=67,96>\mathrm{F}_{\text {tabel }}=$ 2,40 pada tingkat kepercayaan $95 \%$ $(\alpha=0,05)$ maupun $\mathrm{F}$ tabel $=3,52$ pada tingkat kepercayaan $99 \%(\alpha=0,01)$, sehingga dapat dikatakan bahwa biaya bahan baku $\left(\mathrm{X}_{1}\right)$, biaya tenaga kerja $\left(\mathrm{X}_{2}\right)$ dan biaya overhead $\left(\mathrm{X}_{3}\right)$ secara serempak berpengaruh sangat nyata terhadap penetapan harga jual kopi bubuk (Y).

Hasil analisis pengaruh terpisah (Uji t) diperoleh kesimpulan sebagai berikut. Hasil pengujian secara parsial untuk biaya bahan baku dapat dilihat bahwa $\mathrm{t}_{1 \text { cari }}=0,59<\mathrm{t}$ tabel $=1,75$ pada tingkat kepercayaan $95 \%(\alpha=0,05)$ dan $\mathrm{t}$ tabel $=2,60$ pada tingkat kepercayaan 99\% $(\alpha=0,01$, sehingga biaya bahan baku secara parsial tidak berpengaruh secara
3. Apabila biaya bahan baku dan biaya tenaga kerja dianggap tetap, maka setiap penambahan 1.000.000,- maka akan menyebabkan penetapan harga jual bertambah sebesar Rp 780,-.

Berdasarkan hasil perhitungan diperoleh $\left(\mathrm{R}^{2}\right)=0,8643$ atau $86,43 \%$. Ini berarti faktor biaya bahan baku, biaya tenaga kerja dan biaya overhead mempengaruhi penetapan harga jual kopi bubuk sebesar 86,43 $\%$ sedangkan $13,57 \quad \% \quad$ lagi dipengaruhi oleh faktor-faktor lain yang tidak diteliti dalam penelitian ini. biaya overhead sebesar Rp nyata terhadap penetapan harga jual kopi bubuk.

Hasil pengujian secara parsial untuk biaya tenaga kerja dapat dilihat bahwa $\mathrm{t}_{2}$ cari $=3,60>\mathrm{t}_{\text {tabel }}=1,75$ pada tingkat kepercayaan $95 \%(\alpha=0,05)$ dan $\mathrm{t}$ tabel $=2,60$ pada tingkat kepercayaan $99 \%(\alpha=0,01)$, sehingga biaya tenaga kerja secara parsial berpengaruh sangat nyata terhadap penetapan harga jual kopi bubuk.

Hasil pengujian secara parsial untuk biaya overhead dapat dilihat bahwa $\mathrm{t}_{3 \text { cari }}=-0,01<\mathrm{t}$ tabel $=1,75$ pada tingkat kepercayaan $95 \% \quad(\alpha=0,05)$ dan $\mathrm{t}$ tabel $=2,60$ pada tingkat kepercayaan 99\% $(\alpha=0,01)$, sehingga biaya overhead secara parsial tidak berpengaruh terhadap penetapan harga jual kopi bubuk. 
KESIMPULAN DAN SARAN

\section{Kesimpulan}

1. Rata-rata biaya untuk pembelian biji kopi adalah sebesar Rp 6.803.926,-/Bln, rata-rata biaya untuk pembelian biji jagung adalah sebesar $\mathrm{Rp}$ 2.721.570,/Bln dan rata-rata jumlah total seluruhnya untuk biaya bahan baku adalah sebesar $\mathrm{Rp}$ 9.525.496,-/Bln.

2. Rata-rata jumlah penggunaan tenaga kerja adalah sebesar 24,67 HKP/Bln untuk dalam keluarga dan 130,08 HKP/Bln untuk luar keluarga.

3. Rata-rata biaya overhead adalah sejumlah Rp 4.767.371,-/Bln, dengan jumlah biaya terbesar terdapat dibiaya pembelian solar yaitu sebesar Rp 1.391.216,-/Bln dan biaya terkecil terdapat pada biaya pembelian oli dan gemuk yaitu Rp 224.831,-/Bln.

4. Rata-rata harga kopi bubuk adalah Rp. 41.389,-/Kg pada Tahun 2014-2015.

5. Dari analisis statistik dengan menggunakan Regresi Linear Berganda diperoleh persamaan regresi $\hat{Y}=-49,28-4,38 X_{1}+$ $16,64 X_{2}+0,78 X_{3}$

6. Hasil perhitungan koefisien determinasi menunjukkan bahwa besarnya $R^{2}=0,8643$. Ini berarti variasi terhadap naik turunnya penetapan harga jual kopi bubuk (Y) dipengaruhi oleh biaya bahan baku $\left(\mathrm{X}_{1}\right)$, biaya tenaga kerja $\left(\mathrm{X}_{2}\right)$ dan biaya overhead $\left(\mathrm{X}_{3}\right)$ sebesar $86,43 \%$ dan sisanya sebesar $13,57 \%$ lagi dipengaruhi oleh faktor lain yang tidak ikut diteliti dalam penelitian ini.

7. Hasil pengujian secara serempak dapat dilihat bahwa $\mathrm{F}_{\text {cari }}>\mathrm{F}$ tabel, sehingga dapat disimpulkan bahwa biaya bahan baku $\left(\mathrm{X}_{1}\right)$, biaya tenaga kerja $\left(\mathrm{X}_{2}\right)$ dan biaya overhead $\left(\mathrm{X}_{3}\right)$ secara serempak berpengaruh sangat nyata terhadap penetapan harga jual kopi bubuk (Y).

8. Hasil pengujian secara parsial untuk biaya tenaga kerja dapat dilihat bahwa $\mathrm{t}_{1}$ cari $<\mathrm{t}$ tabel, sehingga biaya bahan baku secara parsial tidak berpengaruh secara nyata terhadap penetapan harga jual kopi bubuk.

9. Hasil pengujian secara parsial untuk biaya tenaga kerja dapat dilihat bahwa $\mathrm{t}_{2}$ cari $>\mathrm{t}$ tabel, sehingga biaya tenaga kerja secara parsial berpengaruh sangat nyata terhadap penetapan harga jual kopi bubuk.

10. Hasil pengujian secara parsial untuk biaya overhead dapat dilihat bahwa $t_{3}$ cari $<t$ tabel, sehingga biaya overhead secara parsial tidak berpengaruh secara nyata terhadap penetapan harga jual kopi bubuk.

\section{Saran}

1. Diharapkan kepada pengusaha pengolahan kopi bubuk agar dapat mengefisienkan lagi penggunaan-penggunaan biaya produksi agar penetapan harga jual kopi bubuk dapat diminimalisir lagi.

2. Diharapkan kepada para pengusaha pengolahan kopi bubuk agar bisa lebih meperhatikan peralatan dan input (kopi bubuk) yang digunakan sehingga kualitas kopi bubuk yang dihasilkan menjadi lebih baik.

3. Diharapkan kepada pemerintah dalam hal ini instansi terkait untuk terus memberi perhatian kepada pengusaha pengolahan kopi bubuk agar usahanya dapat ditingkatkan kearah yang lebih 
baik dalam rangka untuk melayani kepentingan masyarakat dalam mengelola kopi bubuk yang bermutu tinggi sehingga dapat terjual dengan mudah di pasaran.

\section{DAFTAR PUSTAKA}

Anggara, A dan Marini, S. 2011. Kopi Si Hitam Menguntungkan Budi Daya dan Pemasaran. Cahaya Atma Pustaka, Yogyakarta.

Anonimous. 2016. Aceh Timur dalam Angka. Badan Pusat Statistik Aceh Timur. Anoraga, P. \& J. Sudantoko. 2002. Koperasi, Kewirausahaan dan Usaha Kecil. Rineka Cipta, Jakarta.

Edy, P. 2011. Buku Pintar Kopi. AgroMedia Pustaka, Jakarta.

Fajari, I. 2013. Analisis Kelayakan Finansial Usaha Penggilingan Kopi di Kecamatan Idi Rayeuk Kabupaten Aceh Timur. Skripsi Jurusan Agribisnis Fakultas Pertanian Universitas Samudra, Aceh.

Halim, A. 2010. Akuntansi Daerah Sektor Publik. Salemba 4, Jakarta.

Hansen \& Mowen. 2004. Manajemen Biaya, Edisi Bahasa Indonesia. Salemba 4, Jakarta.

Ibrahim, M.Y. 2003. Analisis Kelayakan Bisnis. Rineka Cipta, Jakarta. Kardiman. 2003. Ekonomi. Yudhistira, Jakarta.

Karyana, Y. 2008. Ekonomi SMA. Intersolusi Presindo, Yogyakarta. Mulyadi. 2007. Sistem Akuntansi. Selemba 4, Jakarta.

Nazir, M. 2005. Metode Penelitian. Ghalia Indonesia, Jakarta.

Sadeli, L.M dan Siswanto, B. 2004. Akuntansi Manajemen : Sistem, Proses, dan Pemecahan Soal. Bumi Aksasara, Jakarta.

Soekartawi. 2000. Pengantar Agroindustri. Rajagrafindo Pustaka, Jakarta.
.2005.

Pengantar

Agroindustri. Rajawali Press, Jakarta.

Sugiyono. 2008. Metode Penelitian Bisnis. Alfabeta, Bandung.

， 2010. Metode Penelitian Kuantitatif Kualitatif \& RND. Alfabeta, Bandung.

Sudjana. 2005. Metoda Statistika. Tarsito, Bandung

Su'ud, H dan Sri, Fitri H. 2007. Manajemen Agribisnis. Pena, Banda Aceh. Tjiptono, F. 2002. Strategi Pemasaran. Andy Offset, Yogyakarta.

Umar, H. 2008. Metode Penelitian untuk Skripsi dan Tesis Bisnis Edisi Kedua. Raja Grafindo Persada, Jakarta. 